\title{
CFD-DEM modelling of biofilm streamers oscillations and their interactions in the flow
}

\author{
YUQING XIA ${ }^{1}$, Pahala Jayathilake ${ }^{2}$, Bowen Li $^{1}$, Paolo Zuliani ${ }^{1}$, and Jinju Chen ${ }^{1}$ \\ ${ }^{1}$ Newcastle University \\ ${ }^{2}$ University of Oxford
}

June 9, 2020

\begin{abstract}
Biofilm streamer motion under different flow conditions is important for a wide range of industries. The existing work has largely focused on experimental characterisations of these streamers, which is often time-consuming and expensive. To better understand the physics of biofilm streamer oscillation and their interactions in fluid flow, a CFD-DEM (Computational Fluid Dynamics - Discrete Element Method) model has been developed. The model was used to study the flow-induced oscillations of single and multiple biofilm streamers. We have studied the effect of streamer length on the oscillation at varied flow rates. The predicted single biofilm streamer oscillations in various flow rates agreed well with experimental measurements. Furthermore, we have investigated the effect of the spatial arrangement of streamers on interactions between two oscillating streamers, which have not been achieved previously.
\end{abstract}

\section{Hosted file}

CFD-DEM modelling of biofilm streamers oscillations and their interactions in the flow.pdf available at https://authorea.com/users/331327/articles/458031-cfd-dem-modelling-of-biofilmstreamers-oscillations-and-their-interactions-in-the-flow 

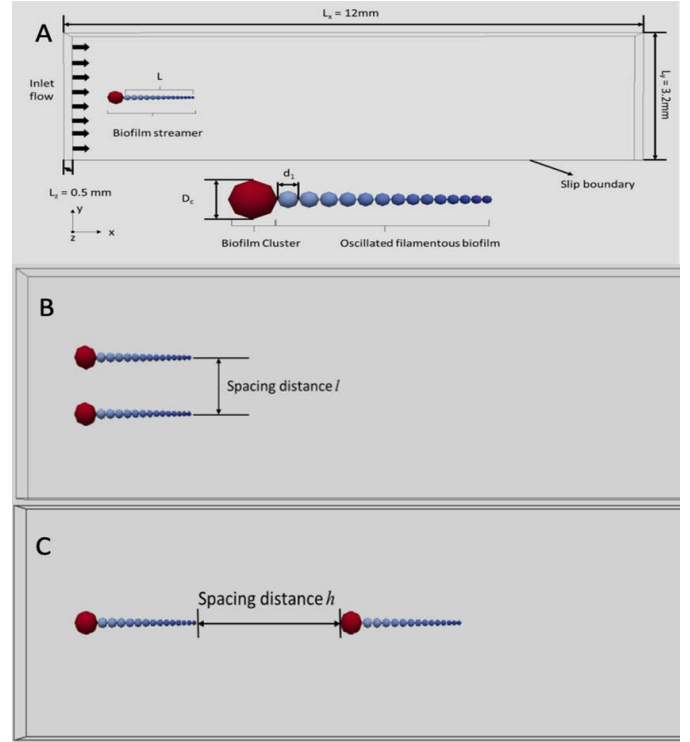

Figure 1: Summary of the model for (A) single biofilm streamer, (B) side-by-side biofilm streamers and (C) in-line biofilm streamers. 